\title{
Cerrahi hastalarının ameliyat öncesi ve sonrasında açlık ve susuzluk düzeylerinin incelenmesi
}

\author{
Selda RIZALAR ${ }^{\mathrm{a}}$, Azize AYDEMIR ${ }^{\mathrm{b}}$, Sacide YILDIZELİ TOPÇU ${ }^{\mathrm{c}}$
}

\section{ÖZET}

\begin{abstract}
Amaç: Bu çalışma cerrahi hastalarının ameliyat öncesi ve sonrası açlık ve susuzluk düzeylerini incelemek amacıyla tanımlayıcı ve kesitsel olarak planlandı. Yöntem: Araştırma 10.03.2014-26.04.2015 tarihleri arasında anket formu ile yüz yüze görüşme tekniği kullanılarak Karadeniz Bölgesi’nde bir üniversite hastanesinde uygulandı. Araştırmanın örneklemine genel anestezi ile planlı ameliyat olan 208 hasta alındı. Hastaların açlık ve susuzluk hissetme düzeyleri Görsel Kıyaslama Ölçeği ile değerlendirildi. Veriler ortalama, standart sapma, yüzdelik, varyans analizi, bağımsız örneklem t testi ile değerlendirildi. Bulgular: Ameliyat öncesinde hastaların susuz bekleme süresi 13.54 \pm 12.76 saat, aç bekleme süresi $14.02 \pm 12.68$ saat; ameliyat sonrasında ise susuz bekleme süresi $30.67 \pm 27.40$ saat, aç bekleme süresi $32.60 \pm 28.5$ saat bulundu. Ameliyat öncesi dönemde hastaların susuzluk puan ortalamas $3.07 \pm 2.80$ açlık puan ortalamas1 $2.36 \pm 2.15$ bulundu. Ameliyat sonrası dönemde hastaların susuzluk puanı $4.27 \pm 3.55$, açlık puanı 3.67 3.03 saptandı. Sonuçlar: Çalışma bulgularına göre cerrahi hastalarında ameliyat öncesi ve sonrası susuzluk ve açlık sürelerinin literatürde önerilenden daha uzun olduğu, susuzluk ve açlık düzeylerinin ameliyat sonrası dönemde orta düzeyde olduğu belirlendi. Ameliyat sonrası susuzluk düzeyinin erkeklerde kadınlardan yüksek, ameliyat öncesi okuryazar olanların susuzluk puanının diğer gruplara göre daha yüksek olduğu belirlendi. Karaciğer, pankreas ameliyatı geçirenlerde ameliyat sonrası susuzluk düzeyinin diğer gruplardan yüksek olduğu saptandı.
\end{abstract}

Anahtar kelimeler: Açlık, ameliyat, cerrahi hemşireliği, susuzluk

\section{Investigation of fasting and thirst levels of surgical patients in preoperative and postoperative periods}

\begin{abstract}
Objective: This study was designed as a descriptive and cross-sectional study in order to investigate preoperative and postoperative levels of fasting and thirst in surgical patients. Methods: The questionnaire was applied to a university hospital in the Black Sea Region between 10.03.2014-26.04.2015 by using face-to-face interview technique. The sample of the study consisted of 208 patients who had been planned for a surgery under general anesthesia. The levels of fasting and thirst were evaluated between with Visual Analog Scale (VAS). Data were evaluated with mean, standard deviation, percentage, variance analysis and independent sample t test. Results: Preoperative thirst time of the patients was $13.54 \pm 12.76$ hours, fasting time was $14.02 \pm 12.68$ hours; postoperative thirst time was found to be $30.67 \pm 27.40$ hours, and the fasting time was $32.60 \pm 28.5$ hours. In the preoperative period, the mean thirst score of the patients was 3.07 \pm 2.80 and the mean fasting score was $2.36 \pm 2.15$. In the postoperative period, the mean thirst score of the patients was found to be $4.27 \pm 3.55$ and the mean fasting score was 3.67 \pm 3.03 . Conclusions: According to the findings of the study, it was determined that the duration of thirst and fasting before and after surgery in surgery patients was longer than recommended in the literature, and thirst and fasting levels were moderate especially in the postoperative period. It was found that the postoperative thirst level was higher in males than that in females, and the thirst scores of literate patients in preoperative period were higher than those in the others. Patients with liver or pancreas operation had higher thirst level than the others in postoperative period.
\end{abstract}

Keywords: Fasting, operation, surgical nursing, thirst

\footnotetext{
Geliș Tarihi: 05.11.2019

Kabul Tarihi:07.12.2019

a'stanbul Medipol Üniversitesi, Sağlı Bilimleri Fakültesi, İstanbul, Türkiye, e-posta: srizalar@ medipol.edu.tr, https://orcid.org/0000 000215929926

${ }^{b}$ Yozgat Bozok Üniversitesi, Sağllk Hizmetleri Meslek Yüksekokulu, Yozgat, Türkiye, e-posta: azize.aydemir@ bozok.edu.tr, https://orcid.org/ 0000 0002 47517088

‘Trakya Üniversitesi, Sağlık Bilimleri Fakültesi, Edirne, Türkiye, e-posta: sacideyildizeli@ trakya.edu.tr, https://orcid.org/0000 000252464355

Sorumlu Yazar/Correspondence: Selda Rizalar e-posta: srizalar@medipol.edu.tr

Çalışma 9.Ulusal Türk Cerrahi Ameliyathane Hemşireliği Kongresinde sözel bildiri olarak sunulmuştur.

Atıf: Rızalar S, Aydemir A, Yıldızeli Topçu S. Cerrahi hastalarının ameliyat öncesi ve sonrasında açlık ve susuzluk düzeylerinin incelenmesi. Sağllk ve Yaşam Bilimleri Dergisi 2019;1(2):32-36.

Citation: Rizalar S, Aydemir A, Yildizeli Topcu S. Investigation of fasting and thirst levels of surgical patients in preoperative and postoperative periods. Journal of Health and Life Science 2019;1(2):32-36.
} 


\section{GíRIŞ}

Ameliyat sırasında mide içeriğinin akciğerlere aspirasyon riskini önlemek, ameliyat sonrasında bulantı kusmayı azaltmak amacıyla ameliyat öncesi dönemde besin ve sıvı kısıtlaması uygulanmaktadır. Açlık süresi bazı hastalarda uzamakta ve istenmeyen sorunlara yol açabilmektedir. Araştırmalar ameliyat öncesi açlık döneminin uzun sürmesinin hastalarda huzursuzluk, baş ağrısı, bulantı, kusma, dehidratasyon, hipoglisemi gibi istenmeyen sonuçlara neden olduğunu göstermiştir. ${ }^{1-3}$ Ağı ve boğazda kuruluk sonucu; konuşma güçlüğü, dudaklarda kuruma ve çatlama, ağız hijyeninde yetersizlik, ağız kokusu görülebilmektedir. ${ }^{4}$ Ayrıca ameliyat öncesi uzun süre aç kalmak; hastanın stresinin artmasına, memnuniyetinin azalmasına, ameliyat sonrası dönemde konforun azalmasına, geç iyileşme ve geç taburculuğa neden olabilmektedir. ${ }^{5,6}$

Ameliyattan önceki birkaç saate kadar berrak sıv1 tüketen hastaların mide volümleri ve $\mathrm{pH}$ 'ları tüm gece aç kalanlarla aynı ya da daha düşüktür., ${ }^{1,9}$ Amerikan Anestezistler Birliği (ASA)'nin 2011-2017 rehberindeki önerilere göre, ameliyattan altı saat önce katı gıdaların, iki saat önce berrak sıvı alımının kesilmesi uygun görülmüştür. Öneriler hastanın yaşına ve alınan besinin özelliğine göre değişmektedir. Ameliyat öncesi açlık süreleri tüm yaş gruplarında berrak sıvılar 2 , bebeklerde anne sütü 4 , mama 6 , inek sütü 6 saat öncesinden ve yetişkinlerde yine 6 saat öncesinden hafif bir yemekle birlikte açlık süresinin yeterli olduğu önerilmektedir. ${ }^{7,10}$ Türk Anesteziyoloji ve Reanimasyon Derneği (TARD)'nin 2015 yilı Anestezi Uygulama Kilavuzları Preoperatif Değerlendirme Klavuzu'nda da ameliyat öncesi açlık süresi literatürdeki rehberlerde belirtilen süreler ile uyumludur. ${ }^{11}$ Avrupa Enteral ve Parenteral Beslenme Derneği (ESPEN) 2017 rehberinde gece boyunca açlık yerine karbonhidratlı içeceklerin alınmasının anksiyete ve insülin direncini azalttığı, ameliyat sonrası iyileşmeyi hızlandırdığı ve hastanede kalış süresini kısalttığı belirtilmektedir. ${ }^{12}$ Ameliyat sonrası dönemde de ilk 24 saat içerisinde oral beslenmenin başlatılmasının yararları ileri sürülmektedir. Erken oral alımın başlatılması iyileşmeyi hızlandırmakta, ağrı düzeyini azaltmakta, hastanede kalış süresini ve maliyeti azaltmaktadır. ${ }^{13,14}$

Ameliyat olan hastalara yönelik oral alımın kısıtlanması konusunda güncel gelişmeler izlenerek bakım verilmeli, öncelikle oral alımı kısıtlanan bireyin açlık süresine yönelik fiziksel ve ruhsal hazırlığına dikkat edilmelidir. Tüm sağlık ekibinin güncel açlık rehberlerini ayrıntısıyla bilmeleri ve hastalarla etkili bir iletişim kurmaları bir iletişim kurmaları gereklidir. Oral kısıtlama, hastanın bakımında bir plan dahilinde uygulanmalı, kaydedilmeli ve gereğinde güncellenmelidir. Tüm bakım sürecinde hastanın rahatı ve güvenliği sağlanmalı, gizliliğine ve onuruna sayg1 gösterilmelidir. ${ }^{4}$ Klinik gözlemler hastaların ameliyat öncesi ve sonrasında aç ve susuz olarak uzun süreler bekletildiği yönündedir. ${ }^{15-17}$ Kliniklerde genellikle hastaların halen gece saat 24.00'ten sonra aç kalma ilkesi benimsenmektedir. $\mathrm{Bu}$ çalışma cerrahi hastalarının ameliyat öncesi ve sonrası açlık ve susuzluk sürelerini ve düzeylerini incelemek amacıyla yapılmıştır.

\section{YÖNTEM}

Tanımlayıcı ve kesitsel tipte olan bu çalışma, Karadeniz Bölgesi'nde bir Üniversite Hastanesi'nde 10.3.2014-26.4.2015 tarihleri arasında yapıldı. Araştırma hastanenin genel cerrahi servisinde yatan, 18 yaş ve üzerinde olan, genel anestezi ile planlı ameliyat geçiren hastalara ameliyat sonrası dönemde taburculuk öncesinde, anket formu ile yüz yüze görüşme tekniği kullanılarak uygulandı. Araştırmanın evreni hastanenin genel cerrahi kliniğinde belirtilen tarihler arasında genel anestezi altında ameliyat olan hastalardan oluşmuştur. Örnekleme genel anestezi altında planlı ameliyat olan, çalışmaya katılmayı kabul eden, 18 yaşından büyük ve enteral/total parenteral beslenme uygulanmayan, araştırmaya katılmayı kabul eden 208 hasta alınmıştır. Hastaların açlık ve susuzluk hissetme düzeyleri Görsel Kıyaslama Ölçeği (GKÖ) ile 0-10 puan arasında değerlendirildi. Veriler araştırmacılar tarafından literatür bilgileri 1şı̆̆ında geliştirilen 15 sorudan oluşan anket formu ile toplandı. 1,7,8,12,13,15,18-20 Veriler, SPSS 16 programında ortalama, standart sapma, yüzdelik, varyans analizi, bağımsız örneklem t testi ile değerlendirildi. Araştırma için hastane yönetiminden 6.03.2014 tarih ve 15374210-929/1046 No'lu izin ve hastalardan açıklama yapıldıktan sonra gönüllü katılım için izin alındı.

\section{BULGULAR}

Çalışmaya alınan bireylerin yaş ortalaması

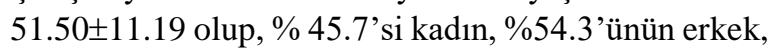
\%48.1'inin ilkokul, \%17.8'inin lise mezunu olduğu belirlendi. Çalışmaya alınan bireylerin tanıları değerlendirildiğinde; \%46.6'sına kolesistektomi/herni/ apendektomi, \%33.2'sine meme/tiroit, \%13.9'una mide/bağırsak, \%6.3'üne karaciğer/pankreas ameliyatı uygulandığ 1 belirlendi. Ameliyat öncesi geceyi \%74'ünün hastanede geçirdiği, oral kısıtlama hakkında \%35.6'sının doktordan, \%26.4'ünün hemşireden, $\% 30.8$ 'inin hemşire ve doktordan bilgi aldıkları saptand1 (Tablo 1).

Ameliyat öncesi dönemde hastaların sivi kisitlama süresi ortalama 13.54 $\pm 12.76(0-72)$, katı gida kısıtlama süresi ortalama $14.02 \pm 12.68$ (6-72) olarak belirlendi. Ameliyat sonrası dönemde ise hastaların sıvı kısıtlama süresi ortalama 30.67 \pm 27.40 (2-96), aç bekleme süresi ortalama $32.60 \pm 28.58$ (4-98) saat olarak bulundu (Tablo 2). 
Tablo 1. Genel cerrahi servisinde yatan hastaların tanıtıcı özellikleri

\begin{tabular}{|c|c|c|c|}
\hline Özellikler & & $\mathbf{S}$ & $\%$ \\
\hline Yaş & $\begin{array}{c}\text { Ort+Ss } \\
51.5 \pm 11.19(27-65)\end{array}$ & & \\
\hline Cinsiyet & $\begin{array}{l}\text { Kadın } \\
\text { Erkek }\end{array}$ & $\begin{array}{r}95 \\
113 \\
\end{array}$ & $\begin{array}{l}45.7 \\
54.3\end{array}$ \\
\hline $\begin{array}{l}\text { Eğitim } \\
\text { düzeyi }\end{array}$ & $\begin{array}{l}\text { Okuryazar değil } \\
\text { Okuryazar } \\
\text { Ilköğretim } \\
\text { Lise } \\
\text { Üniversite }\end{array}$ & $\begin{array}{r}29 \\
15 \\
100 \\
37 \\
27 \\
\end{array}$ & $\begin{array}{r}13.9 \\
7.2 \\
48.1 \\
17.8 \\
13.0\end{array}$ \\
\hline Tanı & $\begin{array}{l}\text { Gastrektomi, kolektomi } \\
\text { Kolesistektomi } \\
\text { Karaciğer, pankreas } \\
\text { operasyonu } \\
\text { Mastektomi, tiroidektomi }\end{array}$ & $\begin{array}{l}29 \\
97\end{array}$ & $\begin{array}{l}13.9 \\
46.6\end{array}$ \\
\hline $\begin{array}{l}\text { Oral } \\
\text { kısıtlaması } \\
\text { hakkında } \\
\text { eğitim }\end{array}$ & $\begin{array}{l}\text { Almayan } \\
\text { Doktordan alan } \\
\text { Hemşireden alan } \\
\text { Hemşire ve doktordan alan }\end{array}$ & $\begin{array}{l}15 \\
74 \\
55 \\
64\end{array}$ & $\begin{array}{r}7.2 \\
35.6 \\
26.4 \\
30.8\end{array}$ \\
\hline $\begin{array}{l}\text { Ameliyat } \\
\text { öncesi gece } \\
\text { kalınan yer }\end{array}$ & $\begin{array}{l}\text { Hastane } \\
\text { Hastane diş1 }\end{array}$ & $\begin{array}{r}154 \\
54\end{array}$ & $\begin{array}{l}74.0 \\
26.0\end{array}$ \\
\hline
\end{tabular}

Tablo 2. Hastaların ameliyat öncesi ve sonrası açlık ve susuzluk süre ortalamaları

\begin{tabular}{lcccc}
\hline & \multicolumn{2}{c}{ Ameliyat öncesi } & \multicolumn{2}{c}{ Ameliyat sonrası } \\
\hline & Ort \pm Ss & $\begin{array}{c}(\min - \\
\max )\end{array}$ & Ort \pm Ss & $\begin{array}{c}(\min - \\
\max )\end{array}$ \\
\hline $\begin{array}{l}\text { Susuzluk } \\
\text { süresi }\end{array}$ & $13.54 \pm 12.76$ & $0-72$ & $30.67 \pm 27.40$ & $2-96$ \\
\hline $\begin{array}{l}\text { Açlık } \\
\text { süresi }\end{array}$ & $14.02 \pm 12.68$ & $6-72$ & $32.60 \pm 28.58$ & $4-98$ \\
\hline
\end{tabular}

Ameliyat öncesi dönemde hastaların susuzluk puan ortalaması $3.07 \pm 2.80$, açlık puan ortalaması $2.36 \pm 2.15$ bulundu. Ameliyat sonrası dönemde hastaların susuzluk puan ortalaması 4.27 \pm 3.55 , açlik puan ortalaması $3.67 \pm 3.03$ bulundu.

Ameliyat sonrası dönemde kadın ve erkek hastaların ameliyat öncesi ve sonrası açlık ve susuzluk düzeyleri karşılaştırıldığında erkek hastaların GKÖ puan ortalamaları kadınlarınkinden yüksek bulundu; sadece ameliyat sonrası susuzluk düzeyi bakımından fark istatistiksel olarak da anlamlı bulundu $(\mathrm{t}=-2.191$; $\mathrm{p}=0.030)$.

Eğitim düzeylerine göre ameliyat öncesi susuzluk puanları arasındaki fark anlamlı bulundu. Okuryazar olanların ameliyat öncesi susuzluk puanları diğerlerine göre daha yüksekti $(\mathrm{F}=3.622 ; \mathrm{p}=0.007)$. Tanılarına göre incelendiğinde karaciğer ya da pankreas cerrahisi geçirenlerin ameliyat öncesi ve sonrasında susuzluk puanlarının anlamlı şekilde diğerlerinden yüksek olduğu bulundu.

Oral kısıtlanması konusunda eğitim alma durumuna göre ameliyat sonrası susuzluk puanları değerlendirildiğinde eğitim almayan grubun GKÖ puan ortalamasının diğer gruplardan yüksek olduğu görülmüştür; bu fark istatistiksel olarak anlamlı bulunmuştur $(\mathrm{F}=3.292 ; \mathrm{P}=0.022$, Tablo 3$)$.
Tablo 3.Hastaların demografik ve hastalıkla ilgili özelliklerine göre ameliyat öncesi ve sonrası açlık ve susuzluk düzeyleri

\begin{tabular}{|c|c|c|c|c|}
\hline \multirow[t]{2}{*}{ Özellikler } & \multicolumn{2}{|c|}{ Ameliyat öncesi } & \multicolumn{2}{|c|}{ Ameliyat sonrası } \\
\hline & $\begin{array}{l}\text { Susuzluk } \\
\text { düzeyi }\end{array}$ & Açlık düzeyi & $\begin{array}{l}\text { Susuzluk } \\
\text { düzeyi }\end{array}$ & $\begin{array}{l}\text { Açlık } \\
\text { düzeyi }\end{array}$ \\
\hline & Ort \pm Ss & Ort \pm Ss & Ort \pm Ss & Ort \pm Ss \\
\hline \multicolumn{5}{|l|}{ Cinsiyet } \\
\hline Kadın & $2.87 \pm 2.55$ & $2.21 \pm 1.87$ & $3.69 \pm 3.34$ & $3.42 \pm 2.91$ \\
\hline Erkek & $3.24 \pm 3.0$ & $2.48 \pm 2.36$ & $4.76 \pm 3.67$ & $3.89 \pm 3.12$ \\
\hline$t ; p$ & $-0.971 ; 0.332$ & $0.938 ; 0.350$ & $-2.191 ; \mathbf{0 . 0 3 0}$ & $\begin{array}{l}-1.120 \\
0.264\end{array}$ \\
\hline \multicolumn{5}{|l|}{ Eğitim düzeyi } \\
\hline Okuryazar değil & $1.75 \pm 1.24$ & $1.58 \pm 1.32$ & $3.89 \pm 3.58$ & $3.34 \pm 2.96$ \\
\hline Okuryazar & $4.06 \pm 4.00$ & $2.33 \pm 1.29$ & $4.33 \pm 3.19$ & $3.80 \pm 2.62$ \\
\hline Ilköğretim & $2.95 \pm 2.50$ & $2.64 \pm 2.37$ & $4.35 \pm 3.58$ & $3.69 \pm 2.89$ \\
\hline Lise & $4.13 \pm 3.52$ & $2.40 \pm 2.39$ & $5.24 \pm 3.58$ & $4.35 \pm 3.53$ \\
\hline Üniversite & $2.96 \pm 2.66$ & $2.11 \pm 1.96$ & $3.03 \pm 3.36$ & $3.00 \pm 3.11$ \\
\hline$F ; p$ & $3.622 ; 0.007$ & $1.460 ; 0.216$ & $1.617 ; 0.171$ & $\begin{array}{l}0.884 \\
0.475 \\
\end{array}$ \\
\hline \multicolumn{5}{|l|}{ Tanı } \\
\hline $\begin{array}{l}\text { Gastrektomi, } \\
\text { Kolektomi }\end{array}$ & $3.00 \pm 2,81$ & $2.41 \pm 2.24$ & $5.89 \pm 3.48$ & $4.72 \pm 2,96$ \\
\hline Kolesistektomi & $3.02 \pm 2.61$ & $2.58 \pm 2.55$ & $3.95 \pm 3.44$ & $3.59 \pm 3.36$ \\
\hline $\begin{array}{l}\text { Karaciğer,Pankreas } \\
\text { operasyonu }\end{array}$ & $5.23 \pm 4.30$ & $2.00 \pm 1.82$ & $5.92 \pm 4.29$ & $2.76 \pm 1.42$ \\
\hline $\begin{array}{l}\text { Mastektomi, } \\
\text { Tiroidektomi }\end{array}$ & $2.78 \pm 2.60$ & $2.08 \pm 1.45$ & $3.72 \pm 3.37$ & $3.52 \pm 2.72$ \\
\hline$F ; p$ & $2.906 ; \mathbf{0 . 0 3 6}$ & $0.853 ; 0.467$ & $3.906 ; \mathbf{0 , 0 1 0}$ & $\begin{array}{l}1.635 \\
0.182 \\
\end{array}$ \\
\hline \multicolumn{5}{|l|}{ Eğitim } \\
\hline Almayan & $1.93 \pm 1.98$ & $2.13 \pm 2.03$ & $5.86 \pm 3.87$ & $5.20 \pm 2.93$ \\
\hline Doktordan alan & $3.05 \pm 2.63$ & $2.01 \pm 1.86$ & $3.89 \pm 3.59$ & $3.32 \pm 3.08$ \\
\hline Hemşireden alan & $3.20 \pm 3.21$ & $2.36 \pm 2.37$ & $3.47 \pm 3.12$ & $3.29 \pm 2.85$ \\
\hline $\begin{array}{l}\text { Doktor ve } \\
\text { hemşireden alan }\end{array}$ & $3.26 \pm 2.77$ & $2.81 \pm 2.26$ & $5.03 \pm 3.60$ & $4.06 \pm 3.05$ \\
\hline$F ; p$ & $0.964 ; 0.411$ & $1.644 ; 0.180$ & $3.292 ; \mathbf{0 . 0 2 2}$ & $\begin{array}{l}2.273 \\
0.081\end{array}$ \\
\hline
\end{tabular}

\section{TARTIŞMA}

Çalışmamızda oral kısıtlama hakkında hastaların \%35.6'sının doktordan, \%26.4'ünün hemşireden, $\% 30.8$ 'inin hemşire ve doktordan bilgi aldıkları saptandı. Demirdağ ve Karaöz'ün çalışmasında ise hastaların \%68.8'inin oral kisitlaması konusunda hemşireden bilgi aldığ1, bilgi alanların \%59.4'ünün verilen bilgiyi yetersiz bulduğu ve ayrıntılı bilgi istediğ $i^{3}$, Dolgun ve ark.'nın çalışmasında ise hastaların çoğunluğunun bilgi aldığ 1 , ancak içeriğinin sadece gece yarısından sonra bir şey yenilmemesi şeklinde olduğu belirtilmektedir. ${ }^{15} \mathrm{Bu}$ durumda ülkemizde ameliyat öncesinde oral kisitlama konusunda hastaların yarıdan fazlasına hemşireler tarafindan bilgi verildiği fakat verilen bilginin yetersiz olduğu görülmektedir.

Dolgun ve ark.'nın çalışmasında hastaların ameliyat öncesinde en önemli yakınması susuzluk olarak bildirilmiştir. ${ }^{15}$ Demirdağ ve Karaöz'ün çalışmasında da susuzluk en sıkıntı verici yakınma olarak belirtilmiştir. ${ }^{3}$ Çalışmamızda ameliyat öncesi dönemde hastaların susuzluk puan ortalaması 3.07, açlik puan ortalaması 2.36 bulunmuş olup ameliyat öncesi susuzluk puanları açlık puanlarına göre daha yüksektir. Dolgun ve ark. ameliyat öncesinde hastaların \%47.6'sının susuzluk, \%30'unun açlık hissettiğini ${ }^{15}$, Gürkan ve Yağcıoğlu hastaların yarıdan fazlasının orta şiddette susuzluk ve açlik hissettiklerini saptamışlardır. ${ }^{21} \mathrm{Bu}$ çalışmada ameliyat öncesi dönemde hastaların susuz bekleme süresi ortalama 
13.5, katı gida almama süresi ise ortalama 14 saat bulunmuştur. Ülkemizde yapılan araştırmalar incelendiğinde; Gürkan ve Yağcıŏlu ${ }^{21}$ ameliyat öncesinde hastaların 14.4 saat sıv1, 16.6 saat katı gida almadıklarını, Dolgun ve ark. ${ }^{15}$ hastaların ameliyata girinceye dek ortalama 12.2 saat s1v1, 13.5 saat katı gıda almadıklarını, Karaöz ve Demirdag $\breve{g}^{3}$ ise 13.6 saat sıv1 ve 14.7 saat katı gida almadıklarını belirlemişlerdir. Tosun ve ark.'nın çalışmasında ameliyat öncesi açlık süresi $14.70 \pm 3.14$ ve sıv1 kısıtlama süresi $11.25 \pm 3.74$ saat bulunmuştur. Ameliyat öncesi hastaların \%58.6'sını orta düzeyde anksiyete yaşadığını, açlık süresi 12 saatten daha uzun olan hastaların; açlık, susuzluk, bulantı ve ağrı puanlarının, açlık süresi daha kısa olanlardan yüksek olduğunu belirlemişlerdir. ${ }^{16}$

Arı ve Yılmaz'ın çalışmasında ameliyattan önce aç kalma süresi $10.9 \pm 5.7$ saat olarak bulunmuştur. ${ }^{22}$ Crenshaw ve Winslow, hastaların ameliyat öncesi ortalama açlık sürelerinin 12-14 saat olduğunu, bu sürenin sıvılar için 20, katılar için 37 saate kadar uzayabildiğini saptamışlardır. ${ }^{1}$ Furrer ve ark. tarafından ortalama oral kısıtlama süreleri sıvılar için 12.8, katı gıdalar için 15.5 saat olarak belirlenmiştir. ${ }^{23}$ Power ve ark.'nın çalışmasında ameliyat öncesi besin/sıvı kısıtlama süresi kısa olan hastaların daha az susuzluk deneyimledikleri görülmüştür. ${ }^{24}$ Demirdağ ve Karaöz'ün çalışmasında hastaların ameliyat öncesi susuz/aç kalma süreleri ile susuzluk/açlik puanları ilişkili saptanmıştır. ${ }^{3}$ Çalışmamızda aç kalma süresi literatürde yer alan bulgular ile benzer bulunmuştur. Ameliyat öncesi dönemde hastaların daha kısa süre aç kalmaları açlık ve susuzluk hissini azaltarak hasta konforunu arttıracağı gibi ameliyat sonrası komplikasyonları da azaltacaktır.

Ameliyat sonrası dönemde oral alım, bulantı kusmayı önlemek ve bölgenin besin ile temas etmeden önce iyileşmesine firsat tanımak için geciktirilebilmektedir. Klinik çalışmalar cerrahi sonrası oral beslenmenin kısıtlanmamasının gerektiğini ve olabildiğince erken beslenmenin daha faydalı olduğunu bildirmektedir. ${ }^{13,19}$ Ameliyat sonrası ilk 12-24 saatlik sürede beslenmenin başlatılması önerilmektedir. Çalışmamızda ameliyat sonrası dönemde hastaların susuz bekleme süresi ortalama 30.6 saat, aç bekleme süresi ise ortalama 32.6 saat bulunmuştur. Arı ve Yılmaz'ın çalışmasında, ameliyattan sonra ilk oral alım süresi $11.7 \pm 18.6$ saattir. $^{22}$ Erken beslenmenin cerrahi sonras1 hızlandırılmış iyileşme uygulamaları ile birlikte uygulandığında postoperatif ileusu azalttığı bilgisi birçok çalışmada yer almaktadır. ${ }^{13,18,19}$

Çalışmamızda ameliyat sonrası dönemde hastaların susuzluk puan ortalaması 4.27 açlık puan ortalaması 3.67 bulundu. Demirdağ ve Karaöz'ün çalışmasında susuzluk puanı $4.45 \pm 3.17$, açlık puanı $3.12 \pm 3.17$ bulunmuş olup aynı zamanda hastalar için susuzluğun tüm diğer rahatsızlıklardan daha çok sıkıntı verici olduğu bildirilmiştir. ${ }^{3}$ Çalışmada ameliyat sonrası dönemde kadın ve erkek hastaların ameliyat öncesi ve sonrası açlık ve susuzluk düzeyleri karşılaştırıldığında, erkek hastaların GKÖ puan ortalamaları kadınlarınkinden yüksek; ayrıca ameliyat sonrası susuzluk düzeyi puanları arasındaki farkın da istatistiksel olarak anlamlı olduğu bulundu. Ancak bu konuda literatür incelendiğinde erkeklerin susuzluğa kadınlardan daha duyarlı olduğunu belirten araştırma bulgusuna rastlanmadı. Eğitim düzeylerine göre ameliyat öncesi susuzluk puanları arasındaki fark anlamlı bulundu. Okuryazar olanların ameliyat öncesi susuzluk puanları diğer eğitim gruplarına göre daha yüksekti. Oral kısıtlama konusunda eğitim alma durumuna göre ameliyat sonrası susuzluk puanları değerlendirildiğinde, eğitim almayan grubun GKÖ puan ortalamasının diğer gruplardan yüksek olduğu görülmüştür; bu fark istatistiksel olarak anlamlı bulunmuştur. Eğitim almayan grupta önceden S1v1 kısıtlamasının gerekçeleri açıklanmadığı için susuzluk puanının daha yüksek çıkmış olabileceği düşünülmüştür. Tanılarına göre incelendiğinde karaciğer ya da pankreas cerrahisi geçirenlerin ameliyat öncesi ve sonrasında susuzluk puanlarının anlamlı şekilde diğer girişimleri geçirenlerden yüksek olduğu saptandı. Bu hastalarda kan glukoz düzeyi yüksekliği nedeniyle de susuzluk hissinin artabileceği düşünülmektedir.

\section{SONUÇ VE ÖNERÍLER}

Çalışma bulgularına göre genel cerrahi hastalarında ameliyat öncesi ve sonrası susuzluk ve açlık sürelerinin literatürde önerilenden daha uzun olduğu, susuzluk ve açlık düzeylerinin özellikle ameliyat sonrası dönemde orta düzeyde olduğu belirlenmiştir. Ameliyat sonrası susuzluk düzeyinin erkeklerde kadınlardan daha yüksek olduğu, ameliyat öncesi susuzluk düzeyinin okuryazar hastalarda diğerlerinden daha yüksek olduğu bulunmuştur. Karaciğer ve pankreas ameliyatı geçirenlerde ameliyat sonrası susuzluk düzeyinin daha yüksek olduğu belirlenmiştir. $\mathrm{Bu}$ sonuçlara dayanılarak hastaların uzun süren açlık susuzluk sürelerinin kısaltılması amacıyla hastanelerde güncel rehberlerin kullanımı konusunda hizmet içi eğitim yapılması önerilebilir.

\section{KAYNAKLAR}

1. Crenshaw JT, Winslow EH. Preoperative fasting: Old habits die hard. American Journal of Nursing. 2002;102(5):36-44.

2. Tudor G. Fasting: How long is too long? Australian Nursing Journal. 2006;13(7):29-31.

3. Demirdağ H, Karaöz S. Ameliyat öncesi besin/ sıvı kısıtlamasına ilişkin hastaların deneyimleri ve hemşirelerin konu ile ilgili bilgi ve uygulamaları. F.N. Hem Derg. 2015;23(1):1-10.

4. Liddle C. Nil by mouth: best practice and patient education. http://www.nursingtimes.net/Journals/ 2014/06/20/r/m/t/250614-Nil-by-mouth-best- 
practice-and-patient-education.pdf. Erişim Tarihi 27.10.2015

5. Nygren J1, Thorell A, Ljungqvist O. Preoperative oral carbohydrate nutrition: An update. Curr Opin Clin Nutr Metab Care. 2001;4(4):255-259.

6. Gök F, Yavuz Van Giersbergen M. Ameliyat öncesi aç kalma: Sistematik derleme Pamukkale Tip Dergisi. 2018;11(2):183-194. doi: $10.5505 /$ ptd.2017.50490.

7. American Society of Anesthesiologists Committee. American Society of Anaesthesiologist task force on preoperative fasting. Practice guidelines for preoperative fasting and the use of pharmacologic agents to reduce the risk of pulmonary aspiration: application to healthy patients undergoing elective procedures. Anaesthesiology. 2011;114(3):495-511.

8. Baril P, Portman, H. Preoperative fasting: Knowledge and perceptions. AORN Journal. 2007;86(4):609-617.

9. Stuart PC. The evidence base behind modern fasting guidelines. Best Practise \& Research Clinical Anaesthesiology. 2006;20(3):457-469.

10. ASA 2017. Practice Guidelines for Preoperative Fasting and the Use of Pharmacologic Agents to Reduce the Risk of Pulmonary Aspiration: Application to Healthy Patients. Undergoing Elective Procedures. Anesthesiology. 2017;126: 376- 393.

11. TARD 2015. Türk Anesteziyoloji ve Reanimasyon Derneği (TARD) Anestezi Uygulama Kilavuzlar Preoperatif Değerlendirme, 2015.

12. Weimann A, Braga M, Carli F et al. ESPEN guideline: Clinical nutrition in surgery. Clinical Nutrition. 2017;36:623-650.

13. Andersen HK, Lewis SJ, Thomas S. Early enteral nutrition within $24 \mathrm{~h}$ of colorectal surgery versus later commencement of feeding for postoperative complications. Cochrane Database Syst Rev. 2006;18(4):CD004080.

14. Spanjersberg WR, Reurings J, Keus F, van Laarhoven CJ. Fast track surgery versus conventional recovery strategies for colorectal surgery. Cochrane Database Syst Rev. 2011;16(2):CD007635. doi: 10.1002/14651858. CD007635.pub2

15. Dolgun E, Taşdemir N, Ter N, Yavuz M. Cerrahi hastalarının ameliyat öncesi aç kalma sürelerinin incelenmesi. F. U. Să̆ Bil Tip Derg. 2011:25(1): 11-15.

16. Tosun B, Yava A, Açıkel C. Evaluating the effects of preoperative fasting and fluid limitation. International Journal of Nursing Practice. 2014;21(2):1-10. doi:10.1111/ijn.12239.

17. Çeçen D, Koca Kutlu A, Yılmaz E. Cerrahi hastalarının ameliyat öncesi dönemde aç kalma durumlarının incelenmesi. İçinde Ed: Yavuz M, Özbayır T Demir Korkmaz F, Kaymakçı Ş. 6. Türk Cerrahi ve Ameliyathane Hemşireliği Kongresi. Kongre Kitabı. 2009 Kuşadas1178-179.

18. Will cuts K, Luwig RB, paludo J, fernandez D, Schrerer F. Lesser time of preoperative fasting and postoperative feeding are safe? ABCD Arg Bras cr Dig. 2013;26(1):54-58.

19. Wallström A, Gunilla HF. Facilitating early recovery of bowel motility after colorectal surgery: A systematic review. J Clin Nurs. 2014;23 (1-2):24 44. doi:10.1111/jocn.12258.

20. Yılmaz E. Cerrahi hastalarda ameliyat öncesi açlık sürecinde yeni yaklaşımlar. Ege Üniversitesi Hemşirelik Yüksek Okulu Dergisi. 2009; 25: 105118.

21. Gürkan A, Yağcıoğlu A. Ameliyat öncesi gerçek açlık süresi ve hastanın iyilik haline etkisi 17. Ulusal Cerrahi Kongresi, Ankara, Türkiye, 26 - 29 Mayis 2010, ss.28.

22. Ar1 M, Y1lmaz E. Impact of pre-operative Anxiety on post-operative constipation Turk $J$ Colorectal Dis. 2016;2:39-46. doi:10.4274/tjcd.2014.72677.

23. Furrer L, Ganter MT, Klaghofer R, Zollinger A, Hafer CK. Preoperative fasting times: Patients' perspective. Anaesthesist. 2006;55(6):643-649.

24. Power S. Kavanagh DO, McConnell G ve ark. Reducing reoperative fasting in elective adult surgical patients: case-control study. Ir J Med Sci. 2012;181:99-104. 